\title{
Sepsis por Pseudomonas aeruginosa en un lactante previamente sano
}

\author{
Carmen Sandoval C., Claudia Moreno M. y Katia Abarca V.
}

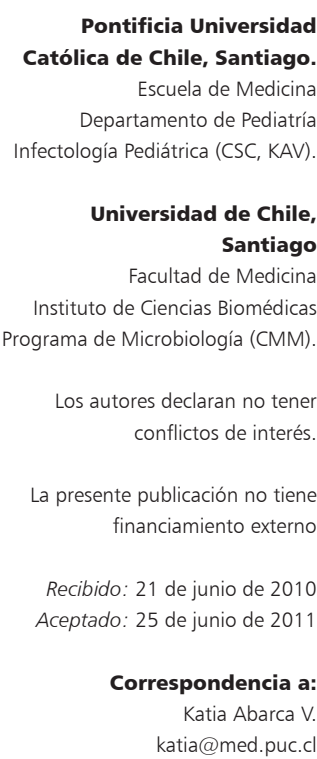

katia@med.puc.c

\section{Introducción}

$P$ seudomonas aeruginosa es un bacilo gramnegativo no fermentador, móvil y aerobio, aunque puede desarrollarse de forma anaerobia utilizando nitrato o arginina. Pertenece a la familia Pseudomonadaceae, género Pseudomonas, siendo la especie $P$. aeruginosa la más prevalente. Es un microorganismo oportunista, de amplia distribución ambiental, presente en la tierra, materia orgánica en descomposición, vegetales y agua. Además se encuentra presente en recintos hospitalarios, principalmente en áreas húmedas como duchas, equipos de ventilación mecánica y equipos de limpieza, entre otros ${ }^{1}$.

Pseudomonas aeruginosa posee varios factores de virulencia, entre los que se encuentran enzimas como proteasas y elastasas. También se ha descrito un sistema de secreción tipo III, que permite inyectar proteínas efectoras al citoplasma de la célula hospedera, produciendo efectos negativos en la función de la barrera epitelial, asociado al desarrollo de disfunción de macrófagos y neutrófilos ${ }^{1}$. Tiene la capacidad de formar una biopelícula, que lleva a una tolerancia antimicrobiana y disminución de la concentración de oxígeno en su interior, produciendo un crecimiento bacteriano lento en fase estacionaria ${ }^{2}$. La formación de la biopelícula se relaciona con la patogenia de infecciones pulmonares crónicas en pacientes con fibrosis quística y bronquiectasias, así como también a infecciones asociadas a dispositivos como catéteres intravasculares o prótesis, interfiriendo con la llegada del antimicrobiano al sitio y la eliminación bacteriana ${ }^{2}$.

Las infecciones invasoras por $P$. aeruginosa generalmente se producen en pacientes con enfermedades subyacentes: patología maligna, inmunodeficiencias, fibrosis quística, quemaduras y niños prematuros ${ }^{3}$. También se presentan con frecuencia en el ambiente intrahospitalario, donde suelen ser resistentes a diversos antimicrobianos. En situaciones excepcionales pueden producirse infecciones adquiridas en la comunidad en pacientes previamente sanos, las que pueden corresponder a la primera manifestación de algún defecto inmunológico no diagnosticado, como hipogamaglobulinemia, neutropenia cíclica y disfunción de los neutrófilos ${ }^{4}$.

Otros factores que favorecen las infecciones invasoras suelen presentarse en el contexto de pacientes con tratamiento corticoesteroidal, uso de ventilación mecánica, infecciones virales, uso de antimicrobianos (favorece cambios en la microbiota intestinal) e infecciones nosocomiales ${ }^{4,5}$.

En personas de la comunidad se han descrito infecciones cutáneas como foliculitis asociada a exposición a fuentes de agua caliente como jacuzzi o piscinas, artritis séptica en usuarios de drogas inyectables, otitis externa que puede ser grave en pacientes diabéticos y en inmunocomprometidos al desarrollar una otitis externa maligna ${ }^{1-6}$.

La mayoría de infecciones graves por $P$. aeruginosa se ven en el contexto hospitalario e incluyen bacteriemia, neumonía, urosepsis e infección de piel con quemaduras. Los pacientes en unidades de cuidados intensivos están especialmente en situación de riesgo de desarrollar estas infecciones, debido a procedimientos invasores y por enfermedades de base. En un estudio norteamericano, $P$. aeruginosa fue el sexto patógeno más frecuente de infecciones intrahospitalarias, la segunda causa de neumonía asociada a ventilación mecánica y la séptima de infección del torrente sanguíneo relacionada a catéter venoso central ${ }^{7}$. 
Pseudomonas aeruginosa posee dos principales mecanismos de resistencia intrínseca a antimicrobianos: expresión de $\beta$-lactamasas AmpC cromosomales, que confiere resistencia a ampicilina, amoxicilina, amoxicilina/ácido clavulánico, cefalosporinas de amplio espectro, cefotaxima y ceftriaxona; diversos sistemas de bombas de eflujo a múltiples fármacos que expulsa antimicrobianos. Para combatir este tipo de resistencia es necesario indicar un antimicrobiano adecuado con la dosis correcta, para evitar ejercer presión selectiva en casos de colonización ${ }^{8}$.

Esta bacteria es capaz de adquirir material genético desde otras bacterias resistentes, por transferencia horizontal de genes. Entre los mecanismos de resistencia adquirida se incluyen la mutación de AmpD, que desreprime AmpC y confiere resistencia a piperacilina, ticarcilina y ceftazidima; la mutación de topo-isomerasa II (gyrA y gyrB) y topo-isomerasa IV (parC y parE) explican la resistencia a quinolonas, inducido mayormente con levofloxacina que con ciprofloxacina. Bombas de eflujo a múltiples antimicrobianos confieren resistencia a cefalosporinas, ureidopenicilinas, fluoroquinolonas y aminoglucósidos; enzimas modificadoras de aminoglucósidos dan resistencia a aminoglucósidos, sulfonamidas, cloranfenicol y $\beta$-lactámicos; enzimas OXA plasmidiales, confieren resistencia a penicilinas antipseudomonas, ceftazidima, cefepime y aztreonam. El gen qnr confiere resistencia a quinolonas y se asocia a resistencia de otras familias de antimicrobianos como $\beta$-lactámicos y aminoglucósidos. Existe información sobre susceptibilidad reducida a carbapenémicos debido a producción de carbapenemasas (metalo-beta-carbapenemasas), pérdida de porina OprD (que disminuye la susceptibilidad a meropenem y da resistencia a imipenem) o por bombas de eflujo (que da resistencia a meropenem y, en menor medida, a imipenem). Estos mecanismos de resistencia involucran un problema particular debido a la emergencia de cepas multi-resistentes (resistencia de tres o más clases de antimicrobianos), resistencia extensa (resistencia a todas menos una o dos clases de antimicrobianos) y cepas pan-resistentes a los antimicrobianos. La alternativa terapéutica de última línea en casos de multi-resistencia a antimicrobianos ha sido colistín; sin embargo, en cepas pan-resistentes no existen alternativas terapéuticas ${ }^{9}$.

Para combatir y evitar la emergencia de resistencia, uno de las principales medidas es el uso racional de antimicrobianos y la prevención y control de las infecciones intrahospitalarias ${ }^{1}$.

Las manifestaciones de la infección por $P$. aeruginosa suelen ser localizadas a nivel cutáneo (foliculitis, celulitis, nódulos subcutáneos, ectima gangrenoso, etc.) asociadas o no a bacteriemia, pudiendo ser de evolución grave y llegando incluso al compromiso multisistémico ${ }^{3,4}$.

El ectima gangrenoso puede o no asociarse a bacteriemia. Se manifiesta inicialmente como una mácula no dolorosa única o en múltiples sitios, que puede evolucionar a una pápula y posteriormente a una bula hemorrágica que al romperse deja una úlcera gangrenosa gris oscura, rodeada con un halo eritematoso. Su patogenia comprende una trombosis arterio-venosa secundaria a la multiplicación bacteriana intravascular ${ }^{10-11}$, secuencia que dura aproximadamente 12 horas (Figura 1). Las lesiones aparecen generalmente en la región anogenital y glútea en $50 \%$ de los casos, aunque pueden presentarse en extremidades en $30 \%$, tronco, axilas y cara ${ }^{4-12}$.

El ectima gangrenoso, desarrollado en el curso de una sepsis es más frecuente en pacientes inmunocompetentes, en quienes se presenta hasta en $64 \%{ }^{4}$, comparado con $5 \%$ en pacientes inmunocomprometidos. Esto se debe, presumiblemente, a que es necesario un sistema inmune adecuado para desarrollar el intenso proceso de inflamación y de necrosis hemorrágica características de esta entidad ${ }^{11}$.

Los factores de mal pronóstico descritos incluyen la instauración tardía de un tratamiento antimicrobiano adecuado, la presencia de neutropenia y de síntomas gastrointestinales, todos estos factores determinados más bien por asociaciones dentro de series clínicas. Cualquier lesión cutánea sugerente de ectima gangrenoso debe ser cultivada y/o biopsiada, debiendo iniciarse tratamiento
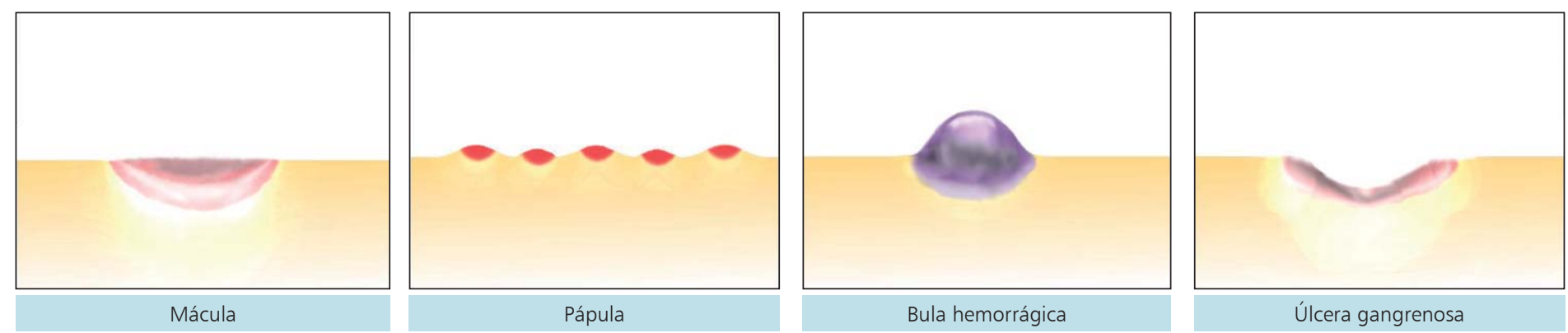

Figura 1. Progresión cutánea de las lesiones por $P$. aeruginosa. Primero aparece una mácula eritematosa, que progresa a pápulas. Luego aparece una bula hemorrágica que al romperse deja una úlcera en la piel. 
Figura 2. Se aprecia ectima gangrenoso en región crural izquierda y muslo derecho en fase avanzada.

Figura 3. Ectima gangrenoso que provoca solución de continuidad "en sacabocado".

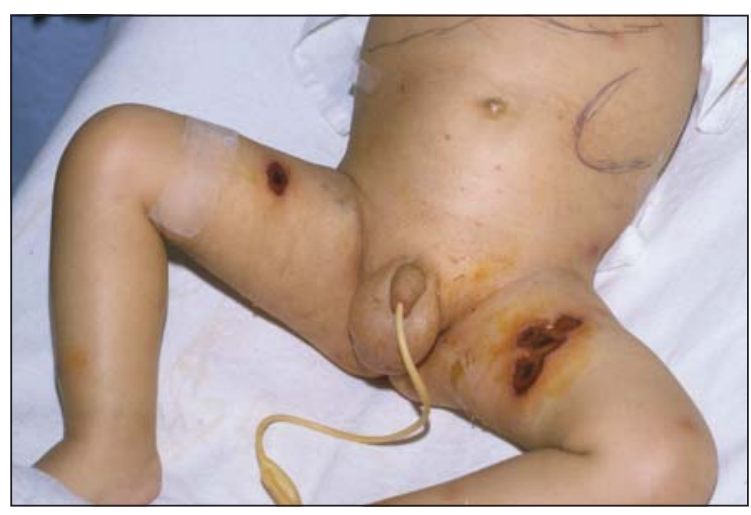

manifestaciones han sido vinculadas al probable origen gastrointestinal de esta sepsis ${ }^{4,5,11}$.

Presentamos el caso de una infección grave por $P$. aeruginosa adquirida en la comunidad en un lactante previamente sano, quien cursó con manifestaciones gastrointestinales, ectima gangrenoso y shock séptico. El estudio descartó una enfermedad de base subyacente.

\section{Caso clínico}

Lactante de sexo masculino de 8 meses de edad, sin antecedentes mórbidos de importancia, con sus inmunizaciones rutinarias al día, que presentó fiebre manejada por su madre con "calitas de cardenal" (tallo vegetal), y vómitos escasos. Luego de dos días de evolución se agregó diarrea, presentando en dos ocasiones deposiciones con aspecto de jalea de grosella. Por mayor compromiso del estado general, somnolencia y decaimiento la madre consultó en el servicio de urgencia, donde se constató taquicardia, compromiso de conciencia y llene capilar lento, por lo cual ingresó a la Unidad de Paciente Crítico Pediátrico iniciándose esquema antimicrobiano con vancomicina y ceftriaxona. Requirió reanimación con apoyo de drogas vasoactivas y ventilación mecánica. El estudio de laboratorio del ingreso mostró un hemograma con leucopenia de 2.000/ $\mathrm{mm}^{3}$ (con RAN: $1.000 / \mathrm{mm}^{3}$ ) asociado a desviación a izquierda (19\% de baciliformes), hematocrito de $23 \%$, plaquetopenia de $91.000 / \mathrm{mm}^{3}$ y una PCR de $13,2 \mathrm{mg} / \mathrm{dl}$ (rango normal $<1 \mathrm{mg} / \mathrm{dl}$ ). Debido al compromiso gastrointestinal se realizó una tomografía axial computarizada (TAC) de abdomen, donde se observaron asas intestinales con edema, mayor en sigmoides y líquido libre intraabdominal. La punción lumbar mostró un estudio citoquímico del líquido cefalorraquídeo normal y la TAC cerebral resultó normal. El cultivo de LCR y el coprocultivo fueron negativos, el urocultivo por sondeo mostró $4.000 \mathrm{ufc} / \mathrm{ml}$ de Escherichia coli susceptible y dos hemocultivos fueron positivos a las 15 horas de incubación, identificándose en ambos $P$. aeruginosa susceptible a los antimicrobianos (amikacina, ceftazidima, ciprofloxacina, piperacilina/ tazobactam, imipenem, meropenem), por lo cual se decidió cambiar a vancomicina, ceftazidima y amikacina.

El paciente evolucionó grave, con shock séptico y edema generalizado, además presentó lesiones violáceas necróticas en extremidades superiores e inferiores con cultivo positivo para $P$. aeruginosa (Figuras 2 y 3 ). Durante el shock séptico, el paciente presentó coagulación intravascular diseminada, alteración de las pruebas hepáticas y trombocitopenia grave, requiriendo múltiples transfusiones. Se realizó desbridamiento de las lesiones cutáneas, descartándose compromiso óseo con resonancia magnética. Cursó con rigidez de la mano derecha secundaria a compromiso tendinoso producto de las lesiones ectimatosas. Se evidenciaron múltiples colecciones 
intraperitoneales, sin evidencias de perforación intestinal. Por gravedad clínica el esquema antimicrobiano fue modificado a vancomicina y meropenem.

El estudio inmunológico realizado con el fin de descartar patologías de base sólo evidenció C4 bajo, el cual se mantuvo hasta dos meses del alta hospitalaria, normalizándose en un control posterior, por lo que se interpretó como secundario a su cuadro séptico. Las imágenes abdominales mostraron presencia de bazo y el resto del estudio inmunológico (inmunoglobulinas totales, subpoblaciones linfocitarias) fue normal; además, superó la neutropenia inicial, en coincidencia con la mejoría clínica.

\section{Discusión}

En una serie de 43 casos pediátricos de sepsis por $P$. aeruginosa en niños previamente sanos, $84 \%$ de ellos fueron niños bajo un año de edad. La manifestación clínica más frecuente fue diarrea y fiebre, presentándose esta última en $70 \%$ de los casos. E1 25\% de los pacientes presentó lesiones de piel como petequias, ectima gangrenoso (50-60\%), pústulas, forúnculos y rash. Un tercio de los pacientes falleció y de éstos la mitad falleció dentro de las primeras 24 horas de ingreso a un centro hospitalario. La leucopenia al ingreso fue el signo más frecuente en los casos fatales, la cual se presentó en más del 90\%. El tratamiento antimicrobiano iniciado en forma empírica, en más del $40 \%$ de los casos fue inadecuado, cifra que se eleva a más del $90 \%$ en los casos fatales ${ }^{4}$.

Prego y colaboradores describen el caso de una niña de 28 meses de edad previamente sana que presentó shock séptico refractario, asociado a neutropenia grave, ectima gangrenoso, enterocolitis necrosante y abscesos hepáticos de evolución fatal ${ }^{12}$. En Taiwán se realizó un estudio retrospectivo de los registros clínicos de 121 niños bajo 15 años de edad, con sepsis, en un período de 15 años (1983-1998), encontrando 43 casos de sepsis por $P$. aeruginosa en pacientes previamente sanos. Los síntomas más frecuentes en esta serie fueron fiebre (91\%) y diarrea ( $72 \%)$; la leucopenia se presentó en 9 de los 10 casos fatales ${ }^{13}$.

El caso presentado corresponde a una sepsis por $P$. aeruginosa adquirida en la comunidad, en un paciente previamente sano. Si bien se trata de una entidad clínica poco frecuente, debe sospecharse la etiología de un agente bacteriano oportunista como es $P$. aeruginosa en situaciones clínicas que presenten ectima gangrenoso, neutropenia y manifestaciones gastrointestinales; debiendo iniciarse tratamiento antimicrobiano empírico con cobertura para este patógeno en forma precoz con el fin de mejorar el pronóstico en estos pacientes.

Un dato interesante asociado al cuadro del paciente fue el uso de una "calita de cardenal" para el manejo del cuadro febril, considerando que Pseudomonas spp habita normalmente en plantas y vegetales como colonizador; actualmente se estudia su probable rol como agente patógeno o regulador biológico ${ }^{14,15}$. Presumimos que esta bacteria pudo estar colonizando el vegetal utilizado lo cual facilitó su adquisición por el paciente. Las manifestaciones clínicas iniciales permiten además plantear la ocurrencia de una invaginación intestinal, la que si bien no estaba presente al momento del estudio de imágenes, pudo haber favorecido alguna perforación intestinal que explicaría la formación de las colecciones abdominales tardías y la permeación de $P$. aeruginosa spp. desde el tubo digestivo a la circulación sanguínea.

A pesar de que existen reportes de casos de pacientes sanos que cursaron con sepsis grave por $P$. aeruginosa, siempre deben investigarse y estudiarse enfermedades de base, que pueden haber pasado inadvertidas clínicamente en forma previa ${ }^{5,6}$.

\section{Resumen}

Pseudomonas aeruginosa es un microorganismo oportunista de amplia distribución ambiental y nosocomial. Las infecciones invasoras se producen generalmente en pacientes inmunocomprometidos; sin embargo, este agente ocasionalmente puede ser causa de sepsis en pacientes inmunocompetentes. Presentamos el caso de un lactante de 8 meses de edad, sin antecedentes médicos, que cursó con un shock séptico por P. aeruginosa. Durante su evolución presentó lesiones de ectima gangrenoso en sus cuatro extremidades, que requirieron múltiples desbridamientos quirúrgicos. En el período agudo presentó neutropenia y complemento $\mathrm{C} 4$ bajo, que normalizó posteriormente. El estudio de inmunidad para descartar inmunodeficiencia fue normal.

\section{Referencias}

1.- Kerr K G, Snelling A M. Pseudomonas aeruginosa: a formidable and ever-present adversary. J Hosp Infect 2009; 73: 338-44.

2.- Folsom J P, Richards L, Pitts B, Roe F, Ehrlich G D, Parker A, et al. Physiology of Pseudomonas aeruginosa in biofilms as revealed by transcriptome analysis. BMC
Microbiol 2010; 10: 294.

3.- Duman M, Ozdemir D, Yiş U, Köroğlu T F, Oren O, Berktaş S. Multiple erythematous nodules and ecthyma gangrenosum as a manifestation of Pseudomonas aeruginosa sepsis in a previously healthy infant. Pediatr Dermatol 2006; 23: 243-6.

4.- Huang Y C, Lin T Y, Wang C H. Communityacquired Pseudomonas aeruginosa sepsis in previously healthy infants and children: analysis of forty-three episodes. Pediatr Infect Dis J 2002; 21:1049-52.

5.- Goolamali S I, Fogo A, Killian L, Shaikh H, Brathwaite N, Ford-Adams M, et al. Ecthyma gangrenosum: an important feature of pseudomonal sepsis in a previously well child. Clin Exp Dermatol 2009; 34: e180-2.

6.- Mull C C, Scarfone R J, Conway D. 
Ecthyma gangrenosum as a manifestation of Pseudomonas sepsis in a previously healthy child. Ann Emerg Med 2000; 36: 383-7.

7.- Hidron A I, Edwards J R, Patel J, Horan T C, Sievert D M, Pollock D A, et al. NHSN annual update: antimicrobial-resistant pathogens associated with healthcare-associated infections: Annual summary of data reported to the National Healthcare Safety Network at the Centers for Disease Control and Prevention, 2006-2007. Infect Control Hosp Epidemiol 2008; 29: 996-1011.

8.- Rice L B. The clinical consequences of antimicrobial resistance. Current Opinion Microbiol 2009; 12: 476-81.

9.- Blondel-Hill E, Henry D A, Speert D P.
Chapter 48: Pseudomonas. Murray P R, Baron EJ, Jorgensen J H, Landry M L, Pfaller M A. Manual of Clinical Microbiology, 9th ed. Washington DC, Editorial Board, 2007, p: 734-48.

10.- Chan Y H, Chong C Y, Puthucheary J, Loh T F. Ecthyma gangrenosum: a manifestation of Pseudomonas sepsis in three paediatric patients. Singapore Med J 2006; 47 (12): 10803.

11.- Zomorrodi A, Wald E R. Ecthyma gangrenosum: considerations in a previously healthy child. Pediatr Infect Dis J 2002; 21 : 1161-4.

12.- Prego J, Bello O, Dufort Y, Álvarez G, De Leonardis D, Sehabiague G, Imbriaco H,
Pizzorno E. Shock séptico por Pseudomonas aeruginosa adquirido en la comunidad asociado a neutropenia, en un paciente previamente sano. Arch Pediatr Urug 2006; 77 (2): 143-8.

13.- Wu B Y, Peng C T, Tsai C H, Chiu H H. Community-acquired Pseudomonas aeruginosa bacteremia and sepsis in previously healthy infants. Acta Paediatr Taiwan 1999; 40: 233-6.

14.- Preston G M. Plant perceptions of plant growthpromoting Pseudomonas Philos. Trans R Soc Lond B Biol Sci 2004; 359: 907-18.

15.- Haas D, Keel C. Regulation of antibiotic production in root-colonizing Pseudomonas spp. and relevance for biological control of plant disease. Annu Rev Phytopathol 2003; 41: 117-53. 